\title{
JEAN-JACQUES ROUSSEAU E A HERANÇA DA NATURALIZAÇÃO DA EXCLUSÃO DAS MULHERES NA CIDADANIA
}

\author{
JEAN-JACQUES ROUSSEAU AND THE HERITAGE OF NATURALIZING THE EXCLUSION \\ OF WOMEN FROM CITZENSHIP \\ JEAN-JACQUES ROUSSEAU Y LA HERANZA DE LA NATURALIZACIÓN DE LA EXCLUSIÓN \\ DE LAS MUJERES EN LA CIUDADANÍA
}

\author{
Edla Eggert ${ }^{1}$ \\ Alexnaldo Rodrigues ${ }^{2}$
}

\begin{abstract}
RESUMO: Nesse artigo apresentamos alguns aspectos históricos do escritor de Emílio que retratam o seu mundo privado, porém altamente político, segundo nossa análise feminista. Problematizamos um Rousseau que, apesar de ter diversos envolvimentos com mulheres de diferentes classes sociais e com distintas implicações na sua vida, não conseguiu admitir a cidadania das mulheres do seu tempo. Analisamos algumas contribuições pedagógicas de Rousseau pouco conhecidas e debatidas por autoras contemporâneas ao filósofo, a serem repensadas na área da Educação, e desenvolvemos nosso argumento sobre a manutenção de uma educação limitadora da cidadania com requintes preconceituosos e machistas sobre as mulheres por esse autor. Finalmente, destacamos algumas das ideias que acenam para a busca por uma educação cidadã para as mulheres.
\end{abstract}

PAlavRAS-Chave: Crítica feminista. Educação. Releitura de clássicos. Mulheres cidadãs.

ABSTRACT: In this article we present some historical aspects about the writer of Emilio which portray his private world, nonetheless highly political, according to our Feminist analysis. We problematize a Rousseau who, despite having several relationships with women from different social classes and with different implications in his life, was never able to admit the reasoning in the thinking of women of his time. We analyze some of Rousseau's pedagogical contributions which are not widely known nor debated by contemporary scholars to rethink them in the field of education, and we develop our argument on the maintenance of a limiting education in terms of citizenship with prejudicial hints and paradoxical ideas about women by this author. Finally, we highlight some of the ideas that point to resistances in search for a citizen education for women.

KEYWORDS: Feminist critic. Education. Rereading of the classics. Citizen women.

RESUMEN: En este artículo presentamos algunos aspectos históricos del escritor de Emilio que retratan su mundo privado, pero altamente político según nuestro análisis feminista. Analizamos un Rousseau que, a pesar de tener diversos envolvimientos con mujeres de diferentes clases sociales y con distintas implicaciones en su vida, no logró admitir la ciudadanía de las mujeres de su tiempo. Analizamos algunas contribuciones pedagógicas de Rousseau poco conocidas y debatidas por autoras contemporáneas a él a ser repensadas en el área de la Educación. Desarrollamos nuestro argumento sobre el mantenimiento de una educación limitadora de la ciudadanía con refinamientos machistas sobre las mujeres por ese autor. Y finalmente, destacamos algunas de las ideas que acenten para la búsqueda de una educación ciudadana para las mujeres.

PAlABRAS ClAvE: Crítica feminista. Educación. Relecturas de clásicos. Mujeres ciudadanas.

Submetido em: 27/08/2018 - Aceito em: 09/09/2018 - Publicado em: 25/01/2019

\begin{tabular}{l|c|c|c|c|c|c} 
(C) Rev. Educ. Perspec. & Viçosa, $M G$ & v. 9 & n. 3 & p.773-792 & set./dez. 2018 & eISSN 2178-8359 \\
\hline
\end{tabular}




\section{INTRODUÇÃO - HISTÓRIAS DE ROUSSEAU AINDA POUCO CONHECIDAS NO BRASIL}

Rousseau é apresentado ao público brasileiro por meio de seus textos, em especial "O contrato social" (ROUSSEAU, 2011) e "Emílio" (ROUSSEAU, 2004), mas não possuímos ainda uma obra com a sua biografia detalhada. O que sabemos é que nasceu em 1712 na cidade de Genebra, era filho de Isaac Rousseau, relojoeiro e mestre de dança, e de Suzanne Bernard. Embora a maior parte dos estudiosos apresente Rousseau quase sem mácula, na área da Educação, Nadja Hermann (2013), Danilo Romeu Streck (2012) e Claudio Almir Dalbosco (2009) lembram que Rousseau se autodefinia como paradoxal. Dentre esses autores, Streck $(2012 ; 2004)$ detalha o que seriam esses paradoxos. Rolando Roque da Silva (2011) é, segundo nosso olhar, dos apresentadores que melhor descreve o que seriam esses "paradoxos" no contexto da vida ordinária do filósofo em estudo.

A família nuclear de Jean-Jacques Rousseau, segundo Rolando Roque da Silva (2011), Paul Johnsonn (2010) e Maria da Glória Pirolla (2001), era constituída por um pai pobre e uma mãe de família rica. Tiveram dois filhos. O primeiro era sete anos mais velho que JeanJacques Rousseau, acabou num internato corretivo e dele não se ouviu falar. A mãe morreu de complicações pós-parto nove dias após o nascimento de Rousseau. O bebê foi entregue à irmã da mãe, que dividia com o pai os cuidados de Jean-Jacques até os oito anos. Juntos, pai e filho, segundo suas memórias descritas no livro "Confissões" e publicado no ano de 1778 (ROUSSEAU, 1988), liam os livros que eram de Suzanne. Depois desse tempo, devido a complicações econômicas enfrentadas pelo pai, o menino foi enviado para um tio, que o encaminhou para junto de um pastor da igreja em Bossei. De lá, segundo Streck (2004), o garoto fugiu e passou por várias casas, chegando, finalmente, na casa de uma das mulheres que lhe daria guarida e proteção. A senhora de Warens o encaminhou para a Itália, depois à Inglaterra e, por fim, a Paris em 1742.

A leitura com o pai foi, segundo o próprio Rousseau, a memória mais afetiva que surgiu desse tempo de infância. Ambos passavam as noites lendo romances deixados pela mulher/mãe. Essa foi, segundo os biógrafos do filósofo, a forma arguta com que Rousseau produziu seus textos, quase como um contraponto ao modelo do que leu. Antes de se tornar escritor, tentou ser gravador, lacaio, seminarista, músico, funcionário público, tutor e copista de música. Rousseau produziu um estilo de escrita de romance epistolar, em forma de cartas, o qual foi um modelo para outros escritores posteriormente.

Em suma, a vida de Rousseau poderia ser considerada como ordinária ${ }^{i}$. Paul Johnsonn (2010) considera que o autor de "Emílio", ou da Educação" (1762) e de "O Contrato Social" (1762) teve uma vida de fracassos e de dependência, em especial, de mulheres. Em certa medida, em

\begin{tabular}{l|c|c|c|c|c|c|} 
(C) Rev. Educ. Perspec. & Viçosa, $M G$ & v. 9 & n. 3 & p.773-792 & set./dez. 2018 & eISSN 2178-8359 \\
\hline
\end{tabular}


boa parte da sua vida, o apoio financeiro de mulheres da aristocracia foi determinante, pois elas garantiram sua vida de escritor. A mais importante foi a Madame de Warens, seguida por Madame Vercellis, Senhora Broglie, a Senhora d'Épinay e, finalmente, Thérèse La Vasseur (SILVA, 2011). Todas atenciosas cuidadoras, além de leitoras e incentivadoras da escrita desse homem moderno.

Madame de Warens (Louise Éléonore de la Tour du Pil - Baronesa de Warens, 1700-1762) residia em Annecy, cidade nos Alpes franceses que fazia divisa com Itália, Suíça e França. Ela foi uma protestante calvinista fugida da Suíça, que se converteu ao catolicismo e conseguiu proteção junto ao rei da Sardenha (NASCIMENTO, 2014). Era separada do marido - no século XVIII - e tinha uma grande missão: receber e instruir protestantes que desejavam converter-se ao catolicismo. E ela teve essa "missão" junto ao aspirante a escritor. Foi a primeira a financiar suas viagens de estudo. Jean-Jacques Rousseau chamava a senhora de Warens de mamãe; porém, para seus biógrafos ela era dubiamente mais que materna: ela seria a grande inspiradora amorosa, pois, conforme Jean-Jacques, era a mais bela e teve destaque nos seus escritos autobiográficos no texto dos "Devaneios do caminhante solitário". Fulvia Maria Luiza Moretto (1994), na introdução do livro "Júlia ou a nova Heloísa" (ROUSSEAU, 1994), publicado pela Editora da Unicamp, narra a curiosa trajetória desse livro, com mais de 600 páginas, escrito tendo por base uma grande paixão que Rousseau viveu. Essa história foi contada por ele 20 anos depois do livro ter sido publicado, por meio de outro livro, intitulado "Devaneios do caminhante solitário no ano de 1776".

Já a senhora Vercellis o contratou como secretário a partir do ano de 1728 até a sua morte; e a Senhora de Broglie também o contratou como secretário do embaixador francês na Itália por volta do ano de 1741. A senhora d'Épinay, foi amiga e protetora e, segundo Rosa Cobo, d’Épinay era escritora e estabelecia contatos com figuras importantes da época, como Voltaire, com quem tinha um relacionamento amoroso. Ela emprestava sua casa de campo para que Rousseau pudesse escrever (COBO BEDIA, 1992). E, com base em seus textos, temos a possibilidade da leitura de alguns indícios do que já ocorria naquela época, ou seja, algumas mulheres da aristocracia não somente financiavam movimentos revolucionários, como também compunham ideias sobre aquele tempo.

Por fim, mas não menos importante, temos a mulher citada por vários biógrafos, a qual merece nossa atenção e sobre a qual já nos referimos: Thérèse La Vasseur. Ela foi, segundo Silva (2011), a companheira com quem Rousseau conviveu praticamente toda sua vida. Foi uma mulher das margens, trabalhadora num hotel onde ele se hospedou. Conheceram-se no ano de 1741. Thérèse La Vasseur conviveu 25 anos de modo clandestino com Rousseau; seu casamento civil ocorreu somente no ano de 1768 e seguiram juntos até a morte dele em 1778 . O casal teve cinco filhos, mas todos entregues na roda dos enjeitados, ou roda dos expostos, pelas mãos de Rousseau. O filósofo analisou esse fato da sua vida no livro "Os devaneios do

\begin{tabular}{l|c|c|c|c|c|c|} 
(C) Rev. Educ. Perspec. & Viçosa, $M G$ & v. 9 & n. 3 & p.773-792 & set./dez. 2018 & eISSN 2178-8359 \\
\hline
\end{tabular}


caminhante solitário", declarando que "[...] isso era o suficiente para me terem transformado em pai desnaturado e, daí, ampliando e afagando essa ideia, pouco a pouco, extraiu-se a consequência evidente de que eu odiava crianças" (ROUSSEAU, 1995, p. 118). Se foi ou não "desnaturado" não temos como julgar, mas para nós, que estamos no século XXI, é possível observar que Rousseau possuía a percepção do que era dito sobre si.

Interessamo-nos por lembrar esses fatos, quase desconhecidos para quem lê "Emílio, ou da Educação". E é justamente a partir deles que buscaremos compreender: Por que um homem como Rousseau, apesar de ter diversos envolvimentos com mulheres de diferentes classes sociais e com distintas implicações na sua vida, não conseguiu perceber a razão no pensamento das mulheres do seu tempo? Ele discutiu e questionou a razão como a possibilidade de um novo amanhecer com luzes racionais, mas não conseguiu criticar o modo como essa razão permanecia intacta no julgamento medieval que a sociedade mantinha sobre as mulheres.

Ao nos debruçarmos no texto sobre a Educação, nos dedicamos a analisar, tendo por base a hermenêutica feminista, alguns aspectos que entendemos serem determinantes para a continuidade da exclusão das mulheres na construção da sua cidadania ainda hoje, século XXI. "Emílio, ou da Educação" é um escrito que merece ser relido com a suspeita de que Rousseau tinha consciência de que as mulheres já reivindicavam seu espaço de reconhecimento e dignidade no pensamento da condição humana. Quando apontamos a suspeita como um elemento para esse estudo, buscamos seguir os passos da hermenêutica feminista (EGGERT, 1999), que sugere alinhavar perguntas que provocam a busca da história e realidade das mulheres do contexto estudado. Além disso, nesse caso da história e realidade educativa das mulheres do tempo de Rousseau, a hermenêutica feminista nos instrumentaliza a pensar o tempo das mulheres de hoje que, em grande medida, ainda lutam por uma educação que considere a autonomia como o fio condutor a ser aprendido no caminho de uma educação para a liberdade.

Essa narrativa sobre a vida pouco conhecida de Rousseau é, para nós, pedagógica, porque é desse modo que conseguimos perceber os conceitos que estavam em processo e constituíam a noção de sociedade da época. Assim, podemos constatar que a noção a respeito das mulheres repetia o que já estava posto como herança da Idade Média e muito anterior, ou seja, a sociedade era ensinada para se manter as mulheres na dependência dos homens. O que podese dizer em relação à compreensão de infância, é que Rousseau introduziu em seu tempo uma compreensão bastante revolucionária. Porém, ao pensar a infância a partir das relações de gênero constatamos uma evidente discrepância na educação para meninos e para meninas. 


\section{A MANUTENÇÃO DE IDEIAS PRECONCEITUOSAS E PARADOXAIS SOBRE AS MULHERES}

A obra deste autor é, sem dúvida, memorável, digna de ser conhecida e estudada. No que se refere à educação, Rousseau é indispensável para compreendermos o tempo da pedagogia moderna. Historiadores, como Franco Cambi (1999) e pensadores brasileiros, como Dermeval Saviani (2010), entre outros o apresentam como o fundamento da construção da pedagogia moderna. Streck (2004, p. 15) relembra que o tecido social em que Rousseau viveu, consolidou "[...] muitas das crenças e das instituições que, hoje são assumidas como 'naturais', desde a família, a educação e a organização do Estado". A obra mais importante para o campo da Pedagogia, é inegavelmente "Emílio, ou da Educação". Contudo, não podemos desconsiderar o segundo livro, "O Contrato Social”, escrito também em 1762.

Para chegar nessas duas obras mais famosas, o escritor teve uma densa trajetória de outras produções. Doze anos antes, em 1750, recebeu o prêmio de um concurso em Dijon, Fr, que tinha como pergunta se o avanço da ciência e das artes contribuía para melhorar os costumes! O título do texto de Rousseau foi "Discurso sobre as ciências e as artes". Até esse ano, Jean Jacques Rousseau produziu textos que remetiam à música, às artes e a outras curiosidades da área das Ciências Humanas em processo de organização, assim como de toda a Ciência.

Rousseau foi preceptor de alguns meninos, secretário da embaixada francesa em Veneza e secretário da família Dupin, para quem trabalhou no empreendimento de escrever uma obra sobre as mulheres (SOËTARD, 2010). Foi nesse período, também, que cultivou amizades com o grupo dos enciclopedistas. Produziu com esses autores textos sobre música, publicados na enciclopédia "Dicionário razoado das ciências, artes e ofícios", obra organizada por Dênis Diderot entre os anos de 1751 e 1772. A outra obra anterior aos livros "Emílio, ou da Educação" e "O Contrato Social" foi "Julia, ou a nova Heloísa" (1761). "Emílio, ou da Educação" e "O Contrato Social" foram escritas no ano de 1762 e foram as que mais produziram polêmicas. Em especial, o texto do "Emílio, ou da Educação", foi queimado em praça pública em Paris no dia 11 de junho daquele ano, e os dois livros também foram queimados em praça pública em Genebra no dia 19 de junho. Moretto (1995) lembra que Rousseau foi persona non grata em quase todos os lugares por onde passou desde esse tempo. Seus textos somente foram retomados com menos paixão e mais interesse acadêmico depois de sua morte. Ele é, sem dúvida, um dos maiores influenciadores das ideias iluministas. Segundo Streck (2012; 2004), o anúncio da noção de um Estado que zelasse pelos mais pobres, por uma escola interessante e pela divisão de faixa etária colocam Rousseau num lugar central da pedagogia moderna.

Concordamos parcialmente com Rousseau quanto a uma afirmação que fez a seu próprio respeito: "[...] digam o que disserem, prefiro ser homem de paradoxos a ser homem de

\begin{tabular}{l|c|c|c|c|c|c|} 
(C) Rev. Educ. Perspec. & Viçosa, $M G$ & v. 9 & n. 3 & p.773-792 & set./dez. 2018 & eISSN 2178-8359 \\
\hline
\end{tabular}


preconceitos" (ROUSSEAU, 2004, p. 96). De fato, Rousseau é um escritor cujas doutrinas são profundamente contraditórias, repletas de frases impactantes, até esdrúxulas e pouco comuns, como mencionamos na introdução deste artigo. Não obstante, boa parte de comentadores especializados contemporâneos, a exemplo de Ernest Cassirer, no ensaio "A questão Jean-Jacques Rousseau", aceitam a asseveração de que as antinomias e aparentes variações de pensamento não comprometem a unidade ou a coerência da totalidade da obra de Rousseau (CASSIRER, 1999).

É possível estabelecer um elo teórico e analítico entre três escritos da produção filosófica de Rousseau, provavelmente os mais significativos, a saber: "O Discurso Sobre a Origem da Desigualdade entre os Homens" (1755), "O Contrato Social" (1762) e o "Emílio, ou da Educação" (1762). Estamos de acordo com o entendimento da indissociabilidade dessas obras, sobretudo quando se busca evidenciar a intencional exclusão da mulher da esfera da racionalidade, da cidadania e da participação política, sob o invólucro de um "princípio estabelecido pela natureza", por laços que, segundo o filósofo, só podiam ser compreendidos em termos lógicos (ROUSSEAU, 2004, p. 516).

Jean-Jacques Rousseau, um dos autores do pensamento liberal-ilustrado, fundamentou filosoficamente a exclusão feminina da esfera pública, uma vez que, ao compararmos as obras "O Contrato Social” e "O Emílio, ou da Educação" não vislumbramos a mulher como sujeito político. Aliás, o preconceito desse autor contra a emancipação feminina se traveste em razão ilustrada, que, por um lado, foi dotada com capacidade para desvelar os mecanismos de sujeição e opressão, mas, por outro, se mostrou inoperante para combater a razão patriarcal; pelo contrário, a reforçou ideologicamente. Alejandra Ciriza (2006, p. 86) analisa que Rousseau não foi sensível perante as desigualdades ligadas entre os sexos e que "[...] a ideia de uma ordem social que baseia sua legitimidade na igualdade não pode justificar a exclusão feminina a não ser através de uma série muito complexa de procedimentos". E o que seria essa série de procedimentos complexos? Buscamos na filósofa política Carole Pateman (1993) algumas análises importantes. A autora revisa em sua obra "O Contrato Sexual", as teorias do contrato social com o fim de dar uma resposta à indagação: Por que, se "todos" nascemos livres e iguais, as mulheres se encontram submetidas? Conforme Pateman (1993), a mulher não estava incluída na teoria do contrato social, ou seja, na ideia de gênese da sociedade e do poder político fundada no acordo tácito ou explícito entre aqueles que concordam e têm a possibilidade de fazer parte de uma mesma sociedade e se submeter a esse poder. Como não poderia ser de outro jeito, dado que, na obra "Emílio, ou da Educação", o próprio Rousseau definiu as mulheres como seres desregrados, frívolos e inconstantes (ROUSSEAU, 2004)? Não poderiam, então, a depender do seu humor, rever uma decisão? Para Rousseau e seu tempo, de fato, elas necessitavam de um tutor. 
Para Pateman (1993, p. 17), a mulher foi excluída mediante um pacto anterior, denominado pela autora de o "contrato original", que "[...] cria duas situações diferenciadas, a liberdade e a dominação. A liberdade do homem e a sujeição da mulher". Para ela, o "contrato original" produz uma situação de liberdade e sujeição, ao ter na sua base dois tipos de contrato. Para os homens, o "contrato social", que os introduz na ordem simbólica da cultura e da sociedade, no reino da liberdade, em que os indivíduos se eternizam e transcendem pelos seus feitos; para as mulheres, o "contrato sexual", que as prefixa na ordem biológica e, por conseguinte, as destina à vida doméstica, à criação dos filhos e ao cuidado dos afetos, ou melhor, as encarcera no reino da necessidade; daquilo que não é relevante do ponto de vista político; do que não deve ser iluminado, mas, sim, protegido, escondido e guardado.

Definitivamente, a ordem da nova sociedade, criada mediante o contrato social, instaura duas esferas separadas: a pública e a privada. Entretanto, a história do contrato social só confere importância à primeira. Todavia, o espaço privado ou doméstico da (re)produção biológica e moral constitui, consoante o pensamento de Rousseau, o fundamento da família como instituição que estabelece a mediação entre o cidadão e o Estado, além de ser responsável pela primeira socialização dos filhos, como também a que possibilita que os valores essenciais para que o varão se torne o cidadão e ascenda ao espaço público.

A nova ordem política supôs a modificação do status do patriarcado ${ }^{\mathrm{ii}}$, não mais derivado do exercício da autoridade paterna, mas, sim, do pacto fraternal entre homens. Isto leva Pateman (1993, p. 120) a afirmar que "[...] O patriarcado moderno é fraternal na forma e no contrato original é um pacto fraternal”. Segundo Pateman (1993), os homens não buscaram somente depor o "governo dos pais", mas também estabeleceram uma fraternidade na ordem política, pela qual teriam a segurança do acesso aos corpos das mulheres. Assim, pela via de um contrato matrimonial, eles não mais estariam reféns dos caprichos do patriarca para tal fim. $\mathrm{O}$ contrato entre o marido e a esposa era, outrossim, um contrato de via única, em que as mulheres consentiam em prestar obediência a seus maridos em troca de proteção (RODRIGUES, 2007). No contrato original, portanto, as mulheres são orientadas por seus maridos e, por conseguinte, não têm o status de indivíduo. Aliás, indivíduo, na teoria democrática, para Pateman (1993), é uma categoria da cidadania liberal patriarcal que denota tanto o domínio de si como o domínio do outro, até mesmo em termos sexuais. Por isso, uma mulher casada passa a ter reconhecimento via o sobrenome do marido, para que tenha o status de indivíduo por meio da tutoria do marido.

Rosa Cobo (1995) acrescenta novos subsídios ao debate inaugurado por Pateman (1993) sobre o pensamento de Rousseau ao focalizar a concepção de "estado de natureza", condição pré-social ou pré-civil que legitima a sociedade construída com base no contrato. Convém ressaltar que a ideia de "estado de natureza" é um raciocínio hipotético explicativo/interpretativo que visa fundamentar o respeito a certos direitos que os homens

\begin{tabular}{l|c|c|c|c|c|c|} 
(C) Rev. Educ. Perspec. & Viçosa, $M G$ & v. 9 & n. 3 & p.773-792 & set./dez. 2018 & eISSN 2178-8359 \\
\hline
\end{tabular}


desfrutavam em um estágio pré-social, como é o caso da liberdade e da igualdade. Vale, aqui, assinalar que o conceito de "estado de natureza" se desdobra em dois sentidos no "Discurso Sobre a Origem da Desigualdade entre os Homens", como analisamos em outro momento (RODRIGUES, 2007), e que ora se remete ao conjunto da espécie humana (estado puro de natureza), e ora diz respeito, diferentemente, a uma parcela sexuada da humanidade (estado histórico de natureza). No último caso, o conceito de estado de natureza serve para descrever a transformação do sexo masculino de um ser selvagem para um ser social, na qual a substituição das ações motivadas pelo instinto dá lugar aos princípios racionais. Aplicado ao sexo feminino, o conceito é utilizado para proceder a completa naturalização da mulher a uma construção de sua dependência e invisibilidade social, por meio da estrita associação entre "mulher" e "mãe", assim como para naturalizar a divisão sexual do trabalho, na qual a mulher, conforme um acordo tácito suposto por Rousseau, orienta que as mulheres são responsáveis pelo âmbito da família.

Como a argumentação é realizada por Rousseau no "Discurso Sobre a Origem da Desigualdade entre os Homens", parece que a mulher, ao longo do processo histórico da humanidade, ficou petrificada, caudatária, refém da espontaneidade dos instintos e da sensibilidade em detrimento da racionalidade, limitada à esfera da reprodução ao invés da esfera da produção. Assim, para Cobo (1995) o "estado pré-social", o "contrato sexual" e o "matrimônio" formam uma amálgama que institui lugares simbólicos e reais no pensamento de Rousseau.

Do mesmo modo, compartilha com esse entendimento Alejandra Ciriza (2006), à medida que o amplia, pois para ela esse pensador entende o estado de natureza como a referência do sujeito político (homem) no livro do "Contrato Social", ao mesmo tempo em que a mulher é a referência do "estado pré-social" do patriarcado.

[...] Embora no estado de natureza haja tanto homens quanto mulheres, o indivíduo masculino será educado sobre o ideal do homem natural. Já para as mulheres, a saída do estado de natureza tem consequências irreparáveis. O trânsito pelo estado pré-social as despojou de força e ferocidade, ligando-as ao espaço doméstico de forma definitiva. Se para o indivíduo masculino, o sujeito político do contrato, o círculo se inicia no estado de natureza para culminar no ingresso à ordem política após a sua educação como homem e cidadão, para a mulher o estado de natureza, única liberdade que conhecerá como fêmea errante, deixa espaço para a reclusão doméstica que já não haverá de abandonar (CIRIZA, 2006, p. 96).

Une-se, aqui, o elo analítico das três principais obras de Rousseau que nos auxilia na reflexão sobre a exclusão das mulheres do exercício da cidadania e participação política. A realização do ideal político exposto no "Contrato" se torna possível mediante um ideal pedagógico que toma como "pano de fundo" o quadro histórico hipotético fornecido pelo "Discurso Sobre a Desigualdade entre os Homens". Deveras, se no "Discurso sobre a Desigualdade" e no "Contrato Social" a questão da individualidade é tematizada, é no "Emílio, ou da Educação"

\begin{tabular}{l|l|l|l|l|l|l} 
(C) Rev. Educ. Perspec. & Viçosa, $M G$ & v. 9 & n. 3 & p.773-792 & set./dez. 2018 & eISSN 2178-8359 \\
\hline
\end{tabular}


que Rousseau afirma a finalidade de seu projeto pedagógico como meio para introduzir o homem no mundo político e assegurar que a mulher esteja no espaço privado. O "Emílio" é "[...] texto de pedagogia que há de construir as pontes entre o sujeito político, um indivíduo abstrato e assexuado, e o sujeito privado, dotado de uma subjetividade densa que inclui crenças, sentimentos, história pessoal, educação, sexualidade, corpo" (CIRIZA, 2006, p. 97). Ademais, como se evidencia com a leitura do Livro V do "Emílio ou da Educação",

[...] o trabalho de dotar Emílio de uma companheira não pode ser deixado ao acaso, de modo que é preciso então educar uma mulher capaz de aceitar em forma voluntária a sujeição à vontade de outro. Contudo, não se tratará de um processo equiparável ao de educação destinado a Emílio, mas sim de uma espécie de domesticação baseada na arbitrariedade (CIRIZA, 2006, p. 97).

Alexnaldo Teixeira Rodrigues $(2007 ; 2016)$ analisa comparativamente a educação de Emílio, menino idealizado no romance de grande sucesso do autor em questão, e de Sofia, futura esposa de Emílio, demonstrando como o projeto pedagógico de Rousseau institui uma educação e moral diferenciada para os sexos a partir de um suporte biológico. Esta divisão contribui para que Emílio e Sofia - enquanto modelos identificatórios do masculino e feminino - tornem-se desiguais e tenham papéis excludentes na sociedade. Rousseau entende que "a educação da mulher deve ser complementar e funcional à educação do homem" (ROUSSEAU, 2004, p. 527), posto que na “[...] união dos sexos cada um concorre igualmente para o objetivo comum, [a felicidade mútua e o bem do Estado,] mas não da mesma maneira" (ROUSSEAU, 2004, p. 516). Tal afirmação do filósofo se apresenta como mecanismo ideológico que serve à manipulação ética, epistemológica e política para projetar um ethos falseado sobre a condição feminina. Afinal, por que, justamente, caberia ao sexo feminino penosas privações e uma educação mais rigorosa em prol da felicidade mútua?

É verdade que a compreensão da distribuição de papéis complementares tradicionais entre homens e mulheres, segundo Rousseau, perpassa o exame das conformidades e diferenças ontológicas entre os sexos: "Em tudo o que não depende do sexo, a mulher é homem: tem os mesmos órgãos, as mesmas necessidades, as mesmas faculdades" (ROUSSEAU, 2004, p. 515). Não obstante, convém ressaltar que as faculdades "não são igualmente partilhadas por eles, mas no conjunto, elas se equilibram” (ROUSSEAU, 2004, p. 526).

Rousseau, então, define o homem e a mulher como antagônicos, não para fazê-los inimigos, mas para uni-los em uma complementariedade sem reciprocidade equivalente. Assim, quanto às conformidades entre os sexos, podemos afirmar, consoante o filósofo, que física e biologicamente homens e mulheres são quase semelhantes, e "[...], sob qualquer ângulo [...] só diferenciam entre si do mais para menos" (ROUSSEAU, 2004, p. 516), o que, quase sempre, coloca o sexo feminino em desvantagem. Ademais, essa assertiva, uma vez mais, desde a perspectiva androcêntrica, revela que o homem é o termo de comparação e a medida através da qual a mulher deve ser avaliada.

\begin{tabular}{l|c|c|c|c|c|c|} 
(C) Rev. Educ. Perspec. & Viçosa, $M G$ & v. 9 & n. 3 & p.773-792 & set./dez. 2018 & eISSN 2178-8359 \\
\hline
\end{tabular}


No que tange a tudo o que diversifica homem e mulher, tal dessemelhança pertence ao sexo (ROUSSEAU, 2004, p. 516); deixa explícito que o sexo é o elemento promotor e distintivo das diferenças entre homens e mulheres: ao homem se destina a potência, a razão e o domínio; à mulher a fragilidade, sensibilidade, devoção e submissão. A influência do sexo se faz sentir muito mais no feminino, que, por ser concebido como puro sexo (ROUSSEAU, 2004, p. 521) é por ele condicionado. A "natureza da mulher", declara Rousseau no "Emílio", é facilmente apreendida pela constituição física que apresenta. O útero e os seios determinam o destino feminino, a saber: procriar e proteger (ROUSSEAU, 2004, p. 519; 521). O corpo masculino é menos determinado e mais livre em suas escolhas (ROUSSEAU, 2004, p. 521).

A diferença conduz a uma finalidade irredutível das funções para cada sexo, e cuja transgressão é vista como uma ameaça à ordem das coisas. "Naquilo que têm em comum eles são iguais; no que têm de diferente não são comparáveis. Uma mulher perfeita e um homem perfeito não deverem parecer-se pelo espírito mais do que pelo rosto" (ROUSSEAU, 2004, p. 516). As semelhanças e diferenças entre os sexos devem influir sobre o moral, conforme a efervescência da imaginação do filósofo.

Rousseau vai além no desenvolvimento da sua lógica da diferença ao realizar uma transposição simbólica do ato sexual para apoiar o papel ativo do homem e o papel passivo da mulher, ou melhor, para construir um jogo dialético de posições homólogas, que semelhante na diferença, são suficientes concordes para se sustentarem mutuamente, a saber: fortaleza e debilidade, domínio e submissão, ataque e defesa, audácia e timidez (ROUSSEAU, 2004, p. 516-517). Um jogo dialético que coloca a mulher, posteriormente, ainda que do lado mais fraco, sentir-se como essencial na vida do homem na medida em que oferece o seu corpo, cuidados e ternura para satisfazer o prazer masculino, obrigando o homem a agradá-la para consentir em deixá-lo ser senhor (ROUSSEAU, 2004, p. 519). Dando certa dignidade à luxúria masculina, Rousseau insiste que o homem não deveria exercer a sua força, mas depender da vontade da mulher, quando almeja o prazer com ela. Todavia, o filósofo se perde em seu pensamento. Ele opera com o conceito de desigualdade dentro da igualdade; distingue mandar do guiar, o papel de ministro e de chefe de governo, pelo que não consegue se desvincular do emaranhado de mando e submissão que se estabelece com a presença da desigualdade homem-mulher. Para Rousseau, a família estava ligada à sociedade por meio do chefe e essa liderança determinava toda a família. E era natural que a mulher obedecesse ao homem, pois ela era considerada inferior naturalmente. Desse modo, se a ordem da natureza e a ordem da sociedade concordassem, tudo seguiria seu curso, normal. Embora, nesse caso, obedecer ao mando de seu marido não tirava da mulher e esposa o direito ao governo desse homem e marido dentro de casa. Para ele, havia uma sutil diferença entre mandar e governar aquele que manda, haja vista que a dominação da mulher era um "domínio de doçura, de habilidade e de complacência; suas ordens são carícias, suas ameaças são lágrimas. Ela deve 
reinar no lar como um ministro no Estado, fazendo com que ordenem o que quer fazer" (ROUSSEAU, 2004, p. 598).

Outrossim, Rodrigues (2007, p. 170-171, grifos do original) elucida o que essa analogia implica no campo político o exercício da cidadania:

[...] o mando e a determinação surgem do corpo político que se forma pelo pacto social e o governo é o corpo artificial sujeito à vontade geral. Seguindo esta analogia, do mesmo modo que o governo deve estar sujeito à vontade geral, a mulher deve estar sujeita ao homem. Quando a vontade geral legisla o governo executa, ou seja, quando o homem manda a mulher obedece. Em termos normativos o governo deve obedecer ou desejar satisfazer ao que lhe manda a vontade geral. Por uma operação lógica deduzimos desta vez, que a mulher deve almejar, desejar, o que quer o homem. No âmbito público, a legitimidade do poder descansa no corpo soberano e no âmbito privado a legitimidade do poder, por inferência, apoia-se no varão. A mulher, desta sorte, não tem legitimidade para determinar coisa alguma, sua legitimidade está em sua sujeição. Sujeição que opera tanto no âmbito privado quanto no âmbito público, uma vez que o varão constitui a vontade geral nestas esferas, na medida em que, como indivíduo, leva particularmente a vontade geral para seu o lar; como confraria de varões, institui a vontade geral para as mulheres tomadas como parcela da humanidade.

Segundo Rousseau, a igualdade pretendida pelas mulheres em relação aos homens é sem sentido. Quando a mulher se queixa que a rigidez dos seus deveres se constitui em uma injusta desigualdade estabelecida pelo homem, ela está errada: "[...] tal desigualdade não é uma instituição humana, ou pelo menos não é obra do preconceito, mas da razão", justifica Rousseau (2004, p. 521). Para além, a defesa da igualdade entre os sexos se constitui, para o autor, em degradação, promiscuidade civil e intoleráveis abusos, a substituição dos sentimentos da natureza, sacrificados pelo artifício. A educação estabelecida pelo filósofo de Genebra tem o intuito de acusar as diferenças entre os sexos.

Ora, desde a completude da obra o "Emílio, ou da Educação" a diferença mais chamativa entre homem e mulher é que, enquanto o primeiro é educado para conhecer a estrutura da necessidade e relacionar-se diretamente com ela, para sentir-se habilitado a manter a posse de seus poderes e expressá-los plenamente em todos os aspectos da vida - tendo como guias a sua razão e consciência, sem preocupar-se com os preceitos sociais e a opinião dos demais -, a mulher é educada para experimentar, por meio de um sistema de restrições, sua dependência dos convencionalismos sociais e a sujeição à opinião dos homens. Igualmente, elas são adestradas na arte de agradar, no artificialismo e na ostentação de um saber ornamental destituído de possibilidades de abstração e autonomia. As admoestações e orientações educativas de Rousseau para com as mulheres são indícios daquilo que Mary Wollstonecraft (2016, p. 62) chamou de "extravagante quimera”. Ele sugere a inconstância feminina afirmando e, de certa forma, tornando verdade pedagógica com orientações como as que seguem:

\begin{tabular}{l|l|l|l|l|l|l|} 
(C) Rev. Educ. Perspec. & Viçosa, $M G$ & v. 9 & n. 3 & p.773-792 & set./dez. 2018 & eISSN 2178-8359 \\
\hline
\end{tabular}


A inconstância nos gostos é-lhes tão funesta quanto o entusiasmo e ambos provêm da mesma fonte. Não lhes tireis a alegria, o riso, o ruído, as brincadeiras loucas, mas impedi que se fartem de uns para correr aos outros; não admitais que num só momento da vida elas não conheçam freio (ROUSSEAU, 1999, p. 430).

Rousseau produziu um giro copernicano na educação ao chamar a atenção para a centralidade da criança no processo pedagógico e ao reagir contra a preocupação exclusiva dos fins educativos, sem atender ao emprego dos meios adequados à sua realização, assim como demonstrar que a criança não é uma pessoa adulta em miniatura, mas, ao contrário, tem características e necessidades próprias à sua idade. Entretanto, apesar desses avanços e rupturas que protagonizou na área da Educação, o filósofo se mostrou conservador e retrógrado quanto à educação feminina. Entre o século XVI e primeira metade do século XVIII

[...] a educação feminina avançou lentamente em um percurso que mesclou ousadias e retrocessos, na medida em que as oportunidades e também os espaços de transgressão das normas vigentes se diferenciam de acordo com a posição social que ocupam, a saber: ricas e pobres (RODRIGUES, 2007, p. 45).

Eram, sobretudo, as mulheres da aristocracia que, em razão de um vazio ideológico quanto à feminilidade, se beneficiavam da liberdade ambígua da primeira metade do século XVIII que oscilava entre a liberdade intelectual para investir nos estudos e a interdição do exercício das funções tradicionais masculinas (RODRIGUES, 2007). Contudo, Rousseau - devido a seu poder de persuasão, sua mágica eloquente, seu refinamento sentimental, seu dom de despertar sentimentos foi “o primeiro a teorizar sobre a família burguesa nascente e ao afirmar o mito da maternidade, [...] ganha projeção e consequente adesão das mulheres ricas que esperavam ser amparadas posteriormente pelos filhos homens e também ter um papel significativo no seio da família” (RODRIGUES, 2007, p. 51).

Essa influência se perpetuou até o século XIX. No Brasil, em particular na Bahia do século XIX, o pensamento de Rousseau influenciou o médico baiano José Lino Coutinho, autor da obra "Cartas Sobre a Educação de Cora", que estabelecia novos preceitos à educação da mulher de elite com o fim de regular os espaços de sociabilidade e comportamento feminino, reafirmando a necessidade de serem castas, irrepreensíveis moralmente, boas mães, esposas e donas do lar (REIS, 2000).

É certo que a polêmica contraposição entre natureza direcionada como relação direta para com as mulheres e cultura relacionada com a vida dos homens foi instaurada de modo ainda mais vigoroso a partir de produções filosóficas "modernas". Para Cláudio Almir Dalbosco (2016, p. 9) "[...] podemos encontrar então no pensamento de Rousseau uma justificação moderna do político, na qual se imbricam mutuamente teoria da democracia e teoria da educação", entendemos que é necessário suspeitar/questionar essa "moderna política", pois

\begin{tabular}{l|c|c|c|c|c|c|}
\hline () Rev. Educ. Perspec. & Viçosa, $M G$ & v. 9 & n. 3 & p.773-792 & set./dez. 2018 & eISSN 2178-8359 \\
\hline
\end{tabular}


ela reedita a manutenção da subserviência das mulheres, como argumentamos ao longo do desenvolvimento do presente texto.

Além disso, Rousseau estava num contexto histórico propício para escrever o que escreveu. Mas é certo também que, seguindo os ensinamentos das teóricas da hermenêutica feminista, devemos operar com uma leitura observadora das ausências e suspeitar de indícios nos discursos não hegemônicos (EGGERT, 1999). Rousseau produziu seus escritos possivelmente pelo fato de que alguns homens e uma parte significativa de mulheres estavam apontando para outros modos de ensinar e aprender a ser mulher e homem no seu tempo.

Como contraponto e como evidência de outras ideias que circulavam no tempo de Rousseau, tomamos como recorte analítico argumentos da Senhora d'Épinay. Em carta escrita para o Abade Galiani, ela comentou a obra "Da influência das sociedades sobre o caráter das mulheres" (1772), de Antoine Léonard Thomas (1732-1785), ilustre acadêmico francês.

\begin{abstract}
É bem evidente que os homens e as mulheres têm a mesma natureza e a mesma constituição. A prova disso é que as mulheres selvagens são tão robustas e ágeis quanto os homens selvagens: assim, a fraqueza de nossa constituição e de nossos órgãos pertence certamente à nossa educação, e é uma consequência da condição que nos destinaram na sociedade. Os homens e as mulheres, tendo a mesma natureza e a mesma constituição, são susceptíveis dos mesmos defeitos, das mesmas virtudes e dos mesmos vícios. As virtudes que se quis dar a elas, em geral, são quase todas contra a natureza, que só produzindo pequenas qualidades artificiais, e danos muito reais. Certamente seriam necessárias várias gerações para nos recolocar tais como a natureza nos criou. Poderíamos talvez sair vencedoras; mas os homens perderiam demais. Ficam bem felizes por não sermos piores do que somos, depois de tudo o que fizeram para nos desnaturar por suas belas instituições etc. (D’EPINAY, 1991, p. 137).
\end{abstract}

As críticas de Madame d'Épinay incidem sobre a conceptualização da mulher como ser de natureza governado por seus órgãos, mais precisamente pelo útero, determinadores do caráter inquieto, da variedade de sensações que faziam com que o sexo feminino não alcançasse as capacidades superiores da razão como análise e síntese (RODRIGUES, 2007). D’Épinay defendia que o corpo tem autonomia em relação ao pensamento e que - em anúncio antecipado em duzentos anos do debate feminista ensejado por Simone de Beauvoir - homens e mulheres participam da racionalidade e esta, por sua vez, prevalece sobre qualquer determinação biológica.

Assim como d'Épinay, temos vários outros e bons indícios de textos como os de Olympe de Gouges, que em 1791, segundo as pesquisadoras Gabriella Bonacchi e Angela Groppi (1995), publicou a primeira obra escrita num estilo de texto inclusivo. Gouges, uma das líderes dos clubes de mulheres apoiadoras da Revolução Francesa, acabou guilhotinada no ano de 1793 pelos companheiros de revolução, porque eles não aceitaram as ideias de que as mulheres desejavam e reivindicavam ser cidadãs!

\begin{tabular}{l|c|c|c|c|c|c|}
\hline () Rev. Educ. Perspec. & Viçosa, $M G$ & v. 9 & n. 3 & p.773-792 & set./dez. 2018 & eISSN 2178-8359 \\
\hline
\end{tabular}




\section{RESISTÊNCIAS NA BUSCA POR UMA EDUCAÇÃO NÃO SEXISTA}

A exclusão das mulheres da cidadania emergente no século XVIII era percebida, pelo menos, para algumas delas, como irracional e ilegítima. E foi a partir da apropriação das formulações abstratas de caráter universal e da própria linguagem revolucionária utilizadas para deslegitimar o Ancien, antigo Regime, que as mulheres questionaram a irracionalidade do sistema patriarcal.

Mary Wollstonecraft (1759-1797) na obra "Reivindicação dos Direitos da Mulher" (Vindication of the rights of woman, 1792) - publicada um ano depois de Olympe de Gouges ter escrito, na França, a "Declaração dos Direitos da Mulher e da Cidadania" em 1791 discutiu politicamente a questão da exclusão das mulheres no espaço público a partir do direito à educação. Essa eminente personalidade feminina foi educadora e escritora britânica, considerada mais como a "pioneira", ou melhor, uma das pioneiras do feminismo moderno e que fez de sua trajetória de vida uma ponte para as suas reflexões, focalizando, sobretudo, os aspectos educativos nos quais encontrou fundamento no pensamento pedagógico de Locke e de Rousseau. Ao analisar os seus escritos, percebemos que o seu interesse pela educação, assim como todo o pensamento feminista liberal, tentou romper com a opressão/subordinação das mulheres a partir da compreensão de que essa opressão/subordinação perpassava na socialização das mulheres: "[...] desde o ponto de vista de sua socialização em uma variedade limitada de funções e suposições, e como forma em que a tradição cultural, que persistia em estabelecer uma grande diferença entre a mulher e o homem, impunha o exercício das ditas funções" (BARRETT; PHILLIPS, 2002, p. 14).

Os principais argumentos de Mary Wollstonecraft (2016), na obra "Reivindicação dos Direitos da Mulher", giravam em torno da defesa da unidade da espécie e reivindicação das mulheres como seres racionais tais como os homens. Ela indicava a igualdade entre os gêneros; manteve uma luta radical contra os prejuízos do modelo de educação feminina vigente; imaginava uma educação igual para meninos e meninas; e, desse modo, argumentava em prol da exigência de direitos de cidadania para as mulheres.

O mais interessante é que ela evidenciou o quanto discordava de Rousseau ao recusar a ideia de que a mulher devesse exclusivamente agradar ao homem e ser subordinada a ele. Como se vê no Emílio, a educação de Sofia era concebida somente em função do predomínio do marido. Vale ressaltar que no capítulo V de "Reivindicação dos Direitos da Mulher" Wollstonecraft teceu os paradoxos de tal pensamento.

Mary Wollstonecraft argumentou que Sofia é um modelo de mulher que habitava no imaginário de Rousseau e carece de realidade histórica: Sofia era um ser artificial. Decerto, ela não estava errada, pois foi no início do capítulo V do Emílio que o filósofo de Genebra

\begin{tabular}{l|c|c|c|c|c|c|} 
() Rev. Educ. Perspec. & Viçosa, $M G$ & v. 9 & n. 3 & p.773-792 & set./dez. 2018 & eISSN 2178-8359 \\
\hline
\end{tabular}


fez uma alusão ao aparecimento de Sofia como o advento de Eva no paraíso; porém, ao invés de tirar Sofia da costela do Emílio, ele a criou.

Outro aspecto da crítica de Wollstonecraft a Rousseau é que este, mesmo dando vazão aos sentimentos e, portanto, criticando a razão iluminista, utilizou a sua sensibilidade para degradar a mulher fazendo-a escrava do amor. Nesse sentido, nutriu as suas paixões e produziu a partir de uma fantasia acirrada, deixando a força mental de lado para naturalizar a submissão/dominação da mulher.

Além disso, ela se utiliza das próprias noções de Rousseau, a exemplo de "razão", "natureza" e "virtude", ressignificando-as de forma absolutamente ilustrada. Assim, a noção de razão utilizada pela autora tem como gênese o bom senso (algo distribuído do mesmo modo a toda humanidade) de Descartes, também empregado por Poullain de la Barre como mecanismo de desmascaramento dos prejuízos provenientes da tradição, dos costumes e valores sociais. Mary Wollstonecraft aproveita esse conceito de razão para demonstrar os prejuízos, tidos como inatos, os quais impedem a emancipação feminina. O gosto e a educação destinada a formar mulheres subservientes decorrem da sua socialização, e não no que atestava, por exemplo, Rousseau ao afirmar que as meninas teriam uma inclinação natural pelo "físico da arte de agradar". Este já estava nos adereços e as meninas acabavam por transferir, posteriormente, este comportamento para o seu corpo, priorizando a beleza e a sedução. Seria uma aprendizagem degradante sobre si mesmas, segundo o olhar de Wollstonecraft.

Daniel Miranda (2015, p. 15) refere-se ao texto da "Reivindicação dos direitos das mulheres" como elucidativo da descrição e análise de uma educação escravizante, em que "elas são ensinadas que sua aparência é extremamente importante e, assim, são levadas a cultivar a fraqueza e aquilo que Wollstonecraft chama de sensibilidade".

Decorreu daí outra crítica, a saber: ao estado de natureza de Rousseau. Para Mary Wollstonecraft, o filósofo confundiu a submissão das mulheres aos costumes e à moral como estado de natureza. Ainda conforme a autora, Rousseau apresentou a diferença como desigualdade usando a seguinte operação: o filósofo estabeleceu os deveres de cada sexo e sobre os ditos deveres estabeleceu as inclinações sociais. Wollstonecraft tentou ressignificar o conceito de virtude e romper com a dupla moral ao recorrer ao conceito de virtude em termos kantianos, ou seja, ao afirmar que, se a virtude, como expressão moral, provém da razão, ela deve ser também universal.

Decerto, as bases de um feminismo iluminista, como foi o de Wollstonecraft, proporcionaram ao debate sobre a educação das mulheres "uma noção de sujeito político forte e consciente, a crença na razão e na racionalidade, no progresso político e social, na possibilidade de grandes programas de reforma social" (BARRETT; PHILLIPS, 2002, p. 15). Ao mesmo tempo, estas

\begin{tabular}{l|l|l|l|l|l|l} 
(C) Rev. Educ. Perspec. & Viçosa, $M G$ & v. 9 & n. 3 & p.773-792 & set./dez. 2018 & eISSN 2178-8359 \\
\hline
\end{tabular}


bases possibilitaram a abertura para uma crítica do "'homem' [como] o que vagueia na humanidade, e repassa os falsos universais que se puseram em circulação no pensamento liberal clássico" (BARRETT; PHILLIPS, 2002, p. 15).

Franco Cambi (1999) analisa que autoras como a inglesa Mary Wollstonecraft e a francesa Olympe de Gouges introduziram o que mais tarde se designou feminismo da diferença. Além disso, produziram e ainda produzem uma pedagogia da diferença e estabeleceram a importância de considerar um pensamento a partir das experiências das mulheres e para as mulheres. E, no texto de Wollstonecraft (1792), encontramos os argumentos ainda atuais para uma educação no caminho da autonomia das mulheres que, para ela tinham na independência "a grande bênção da vida e a base de toda a virtude" (WOLLSTONECRAFT, 2016, p. 17).

\section{CONSIDERAÇÕES FINAIS}

Reler a história e analisar a obra de Jean-Jacques Rousseau por meio de uma hermenêutica oriunda dos estudos feministas causa estranhamento e convida para um debate. Todavia é preciso ter presente que a janela aberta pelas feministas liberais possibilita pistas para uma análise sobre o significado desse contexto em que a Sofia, como diz Streck (2004), representa a porta de entrada para a socialização de Emílio. Sob a suspeita feminista, ela não é mais do que a porta de fato! Sofia é a porta que ele abre e fecha quando deseja, porque afinal Emílio é autônomo, e ela é autômata. Ela foi incrivelmente treinada para não perceber a subjugação. A educação de Sofia é para a subserviência. Como reportamos anteriormente, Carole Pateman (1999) lembrou que a tradição moderna introduziu na figura da mulher casada o seu reconhecimento via o sobrenome do marido e que ela passa a ter o status de indivíduo por meio da tutoria do marido, porque é a ele que essa mulher deve obediência. Esse "lembrete" jurídico e teológico em boa medida ainda é ensinado e vigora em nossos dias.

Desconstruir esse legado não tem sido fácil, porém descobrir parceiras como Madame Warens, D’Epinay, De Gouges e Wollstonecraft pode fazer com que luzeiros acendam perspectivas otimistas na produção educativa dessa metade da população que segue no caminho do aprender a se pensar. Não para terem poder sobre os homens, como bem lembra Wollstonecraft (1792), mas para terem poder sobre si mesmas!

A hermenêutica feminista nos inspira a retomar ensinamentos para a subserviência legados de Rousseau e muitos outros "clássicos", para compormos outras formas de trazermos ao debate o que temos insistentemente anunciado como uma educação para a autonomia das mulheres. Quando Wollstonecraft discute estrategicamente o conceito de razão introduzido com o iluminismo, ela demonstra que os argumentos racionais da época relacionaram as mulheres somente com o biológico e dicotomizaram ainda mais o mundo, atribuindo a cultura para os

\begin{tabular}{l|l|l|l|l|l|l} 
(ㅇ Rev. Educ. Perspec. & Viçosa, $M G$ & v. 9 & n. 3 & p.773-792 & set./dez. 2018 & eISSN 2178-8359 \\
\hline
\end{tabular}


homens e a natureza para as mulheres, o que impediu a emancipação destas. A educação para uma estética ao gosto do olhar dos homens (para agradá-los) desequilibra a educação para o ético, e mantém o elemento político (o privado é político) de educar mulheres subservientes numa aprendizagem degradante sobre si mesmas. Portanto, os preconceitos de Rousseau revisitados, tanto por suas contemporâneas, quanto por exercícios como esse a que nos propusemos, são outras releituras que entendemos imprescindíveis para a cidadania das mulheres de todas as realidades e contextos educacionais.

\section{REFERÊNCIAS}

BARRET, Michell; PHILLIPS Anne. Introducción. In: BARRET, Michell; PHILLIPS Anne (Orgs.) Desestabilizar la teoría: Debates Feministas Contemporáneos. México: Paidós, 2002. P 13-23.

BONACCHI, Gabriella; GROPPI, Angela (Org.). O dilema da cidadania. Direitos e deveres das mulheres. São Paulo: Editora UNESP, 1995.

CAMBI, Franco. História da pedagogia. Tradução de Álvaro Lorencini. São Paulo: Fundação Editora da Unesp, FEU, 1999.

CASSIRER, Ernst. A questão Jean-Jacques Rousseau. São Paulo: Unesp, 1999.

CIRIZA, Alejandra. A propósito de Jean Jacques Rousseau: contrato, educação e subjetividade. Filosofia política moderna. De Hobbes a Marx Boron, Atilio A. CLACSO, Consejo Latinoamericano de Ciencias Sociales; DCP-FFLCH, Departamento de Ciências Políticas, Faculdade de Filosofia Letras e Ciências Humanas, USP, Universidade de São Paulo. 2006.

COBO, Rosa. Fundamentos del patriarcado moderno: Jean Jacques Rousseau. Madrid: Cátedra, 1995.

COBO BEDIA, Rosa. Influencia de Rousseau en las conceptualizaciones de la mujer en la Revolución Francesa. In: AMOROS, Celia (Coord.). Feminismo e Ilustración 1988-1992. Actas del seminario permanente. Madrid: Instituto de Investigaciones Feministas Universidad Complutense de Madrid; Dirección General de la Mujer de la Comunidad Autónoma de Madrid, 1992. P. 185-192.

DALBOSCO, Cláudio Almir. O lugar do Émile na arquitetônica do pensamento de Rousseau: Problemas de vínculo entre educação e política. Veritas. Porto Alegre, v. 61, n. 1, p. 7-25, jan./abr. 2016.

DALBOSCO, Cláudio Almir. Paradoxos da educação natural no Emíle de Rousseau: os cuidados do adulto. Educ. Soc., Campinas, v. 30, n. 106, p. 175-193, jan./abr. 2009. 
D'EPINAY, Louise. Carta de Madame D'Epinay ao Abade Galiane sobre o livro de Thomas. In: DIDEROT, Denis; THOMAS, Antoine L.; D'EPINAY, Louise. O que é uma mulher?: um debate. Rio de Janeiro: Nova Fronteira, 1991.

EGGERT, Edla. A mulher e a educação: possibilidades de uma releitura criativa a partir da hermenêutica feminista. Estudos Leopoldenses, São Leopoldo, RS, v. 3, n. 5, p. 19-28, 1999.

HERMANN, Nadja. Virtude e amor em Rousseau. Hist. Educ., Porto Alegre, v. 17, n. 41, p. 29-42, set./dez. 2013.

JOHNSONN, Paul. Jean-Jacques Rousseau... "un loco interesante". In: MONTECINOS, Hernán. Blog. 12 out. 2010. Disponível em: https://goo.gl/vndYLV. Acesso em: 23 mar. 2017.

MIRANDA, Daniel M. Apresentação da obra Reivindicação dos direitos das mulheres. In.: WOLLSTONECRAFT, Mary. Reivindicação dos direitos das mulheres. Tradução e notas de Andreia Reis do Carmo. São Paulo: EDIPRO, 2015.

NASCIMENTO, Rafael Baioni do. Solidão e formação, solidão da formação: reflexões teóricas sobre a possibilidade desprezada pela psicologia. 2014. 220 f. Tese (Doutorado em Psicologia) - Programa de Pós-Graduação em Psicologia, USP, São Paulo, 2014.

PATEMAN, Carole. O contrato sexual. Tradução de Marta Avancini. Rio de Janeiro: Paz e Terra, 1993.

PIROLLA, Maria da Glória Rocha. ... um pouco de Jean-Jacques Rousseau. In: Rousseau: Filosofia, Literatura e Educação. Curso de Extensão Universitária, 2001, UNESP. Anais eletrônicos... São Paulo: UNESP, 2001. Disponível em:

https://goo.gl/6XMQgi. Acesso em: 02 maio 2017

REIS, Adriana Danta. Cora: lições de comportamento feminino na Bahia do século XIX. Salvador: FCJA: Centro de Estudos Bahiano da UFBA, 2000.

RODRIGUES, Alexnaldo Teixeira. Sobre a Educação de Sofia. Contemplação - Revista Acadêmica de Filosofia e Teologia da Faculdade João Paulo II, v. 13, p. 79-95, 2016. Disponível em: https://goo.gl/AdBgmb. Acesso em: 03 maio 2017.

RODRIGUES, Alexnaldo Teixeira. Afinal, para que educar o Emílio e a Sofia? : Rousseau e a Formação Moral dos indivíduos. 2007. 203f. Dissertação (Mestrado em Educação) Faculdade de Educação, Universidade Federal da Bahia, Salvador, 2007.

ROUSSEAU, Jean-Jacques. O contrato social e outros escritos. Tradução Roland Roque da Silva. 21. ed. São Paulo, SP: Cultrix, 2011.

ROUSSEAU, Jean-Jacques. Emílio, ou da educação. São Paulo: Martins Fontes, 2004.

\begin{tabular}{l|l|l|l|l|l|l} 
(C) Rev. Educ. Perspec. & Viçosa, $M G$ & v. 9 & n. 3 & p.773-792 & set./dez. 2018 & eISSN 2178-8359 \\
\hline
\end{tabular}


ROUSSEAU, Jean-Jacques. Discurso sobre a Origem e os Fundamentos da Desigualdade Entre os Homens. In: ROUSSEAU, Jean-Jacques. Os Pensadores. São Paulo: Nova Cultural, v. 2, 1999. P. 17-163.

ROUSSEAU, Jean-Jacques. Os devaneios do caminhante solitário. Tradução Fúlvia Maria Luiza Moretto. São Paulo, SP: HUCITEC; Brasília, DF: Ed. Universidade de Brasília, 1995.

ROUSSEAU, Jean-Jacques. Júlia ou a nova Heloísa: cartas de dois amantes habitantes de uma cidadezinha ao pé dos Alpes. Tradução Fulvia ML Moretto. São Paulo: Hucitec; Ed. da Unicamp, 1994.

ROUSSEAU, Jean-Jacques. Confissões. Tradução Fernando Lopes Graça. Lisboa: Relógio D’Água, 1988.

SAVIANI, Dermeval. Escola e democracia. 42.ed. São Paulo: Cortez; Autores Associados, 2010.

SILVA, Roland Roque da. Biografia. In: ROUSSEAU, Jean-Jacques. O contrato social e outros escritos. Tradução Roland Roque da Silva. 21 ed. São Paulo, SP: Cultrix, 2011.

SOËTARD, Michel. Jean-Jacques Rousseau. Trad. Verone Lane Rodrigues de oliveira. Recife: Fundação Joaquim Nabuco, Editora Massangana, 2010.

STRECK, Danilo Romeu. Rousseau e os paradoxos da educação latino-americana. Cadernos de Educação, Pelotas, n. 41, p. 69-83, jan./abr. 2012.

STRECK, Danilo Romeu. Rousseau e a educação. Belo Horizonte: Autêntica, 2004.

WOLLSTONECRAFT, Mary. Reivindicação dos Direitos da Mulher. Tradução de Ivania Pocinho Motta. 1 ed. São Paulo: Boitempo, 2016.

\section{NOTAS}

\footnotetext{
i A palavra "ordinária", utilizada para qualificar a vida de Rousseau, no feminino, causa o estranhamento ambíguo com a ideia de desordeira, vagabunda, miserável e, simultaneamente possui, no contraponto, a ideia de cotidiano. Misturamos as duas compreensões: o ordinário como cotidiano e como marginal desordeiro. Entendemos que a história de Jean-Jacques Rousseau foi contraditória, excitante e cheia de contraditórios e paradoxos. E, como autores desse texto, comprometidos com a visibilidade da história das mulheres, escreveremos com a perspectiva do que seria a vida ordinária de Rousseau junto dessas com quem ele conviveu. Não há muitos indícios sobre essa faceta da existência de Rousseau. Porém, o que temos nos registros que encontramos pode fazer com que pensemos sobre a delicada e sinuosa complexidade nas relações estabelecidas por ele com as mulheres. A exploração, dominação e subserviência se fizeram presentes e podem ser conferidas nos próprios escritos de Rousseau nas obras "Os devaneios do caminhante solitário" (1776) e "Confissões" (1778).
} 


\begin{abstract}
ii O vocábulo "patriarcal” cristalizou-se na significação da concentração de poder e de prestígio na figura do pai, que havia terminado na forma, mas não consubstancialmente, com base nas contestações dos contratualistas sobre a derivação do poder político com base na procriação (RODRIGUES, 2007).
\end{abstract}

\title{
Sobre os Autores
}

${ }^{1}$ Edla Eggert - Professora na Escola de Humanidades da Pontifícia Universidade Católica do Rio Grande do Sul. E-mail: edla.eggert@gmail.com - ORCID: http://orcid.org/0000-0002-1980-7053

${ }^{2}$ Alexnaldo Rodrigues - Doutor em Estudos Interdisciplinares sobre Mulheres, Gênero e Feminismo. Pesquisador Associado do Núcleo de Estudos Interdisciplinares sobre a Mulher da Universidade Federal da Bahia. E-mail: alexnaldotr@yahoo.com.br - ORCID: https://orcid.org/0000-0003-2118$\underline{1448}$ 